\title{
Dietary Intake of Seven B Vitamins Based on a Total Diet Study in Japan
}

\author{
Toshiaki WAtanABE ${ }^{1}$, Kyoko SuEmura ${ }^{1}$, Ayumi TANiguchi ${ }^{1}$, Shuhei EbarA $^{2}$, \\ Sachiko KIMURA ${ }^{3}$ and Toru FuKUI ${ }^{4}$ \\ ${ }^{1}$ Department of Dietary Environment Analysis, ${ }^{2}$ Department of Nutritional Biochemistry, and \\ ${ }^{3}$ Department of Environmental Biochemistry, School of Human Science and Environment, \\ Himeji Institute of Technology, University of Hyogo, Himeji 670-0092, Japan \\ ${ }^{4}$ Clinical Laboratory, Byotai Seiri Laboratory, Tokyo, 173-0025, Japan
}

(Received January 7, 2010)

\begin{abstract}
Summary The present study estimated the dietary intake of seven B vitamins using a total diet study (TDS) in Japan. The daily intake of vitamins estimated by TDS was calculated based on the mean contents of vitamins in 18 food groups, and the amount of food intake in the Nation Health and Nutrition Survey in Japan, 2006. The estimated daily intake of these vitamins for all ages was $22.8 \mathrm{mg} \mathrm{NE} / \mathrm{d}$ for niacin, $7.4 \mu \mathrm{g} / \mathrm{d}$ for vitamin $\mathrm{B}_{12}, 146 \mu \mathrm{g} / \mathrm{d}$ for folic acid, $4.52 \mathrm{mg} / \mathrm{d}$ for pantothenic acid, $1.06 \mathrm{mg} / \mathrm{d}$ for riboflavin, and $1.44 \mathrm{mg} / \mathrm{d}$ for pyridoxine. The estimated daily intake of the vitamins of niacin, vitamin $\mathrm{B}_{12}$ and pyridoxine exceeded the dietary reference values for adults aged 18-29y. The estimated daily intake of these vitamins by TDS was higher than the daily intake reported in the National Health and Nutrition Survey in Japan, 2006. There was a strongly positive correlation between the intake levels estimated by TDS and those reported in the National Health and Nutrition Survey. This suggests that TDS is an effective dietary survey for estimating the dietary intake of water-soluble vitamins. Therefore, when being determined by TDS, the estimated daily intake of biotin was $51.0 \mu \mathrm{g} / \mathrm{d}$ for all ages.
\end{abstract}

Key Words total diet study, water-soluble vitamins, dietary intake, Japanese, Reference Dietary Intake

There is a close relationship between food and health. Recently, with the westernization of the diet in Japan, mortality caused by "life-style related diseases" such as cancer, cardiovascular disease and diabetes has increased. As a main cause of these diseases, a dietary habit is one of the critical factors. In other words, improving our dietary habits may prevent many of these life-style related diseases. Therefore, it is important to correctly evaluate our dietary habits using dietary assessment methods.

There are many kinds of dietary methods for assessment of the nutritional status of a community, such as dietary records, 24-h dietary recalls, duplicate meals, dietary biomarkers and food frequency questionnaires (FFQs). These methods are applied according to their individual characteristics. For example, the dietary records, 24-h dietary recalls and FFQs are used for the calculation of nutrient intakes, based upon nutrient contents listed in the Standard Tables of Food Composition in Japan (Food Composition Tables) (1). Regarding the nutrients such as biotin, which is not listed in Food Composition Tables, the amounts of nutrients actually contained in food are determined by the duplicate meals or total diet study (TDS) and dietary intakes of the nutrients are calculated.

The TDS has been an important part of the Food and

E-mail: watanabe@shse.u-hyogo.ac.jp
Drug Administration's (FDA) program for monitoring pesticide residues, chemical contaminants and radionuclides as well as playing a part in the National Nutrition Monitoring System for assessing nutrient intakes. The Ministry of Education, Culture, Sports, Science and Technology in Japan also conducts a study to estimate the intake of chemical substances added to and/or contaminating food, such as residual pesticides, in daily life. Although TDS also seems to be suitable for evaluating the intake of micronutrients such as vitamins and minerals, there have only been a few reports estimating the intake of micronutrients by TDS (2-9).

Since the food samples for analysis are mixed and homogenized by food groups as the main characteristics of TDS, the number of foods needed for analysis is less than that in the dietary methods in which each type of food is analyzed separately. Furthermore, it is also pointed out that the amount of nutrient intake is closer to the actual values obtained from eating foods because foods are analyzed through the process of cooking according to how the foods are eaten. The classification of "13 food groups" has been used for measurements in TDS in Japan $(7,8)$. However, in this study, we classified foods into "18 food groups" in accordance with the classification method used in "The National Health and Nutrient Survey in Japan" (10). The findings obtained by this TDS can be easily compared with those reported in the National Health and Nutrient Sur- 
vey in Japan. This study estimated the intake of the seven B vitamins by using TDS (18 food groups) in Japan. As the dietary intake of biotin in particular cannot be calculated by conventional dietary methods, there are few reports about the evaluation of the dietary intake of biotin. Therefore, the dietary intake of biotin was estimated in detail by related factors such as by sex and age.

\section{MATERIALS AND METHODS}

Preparation of samples. In this study, the food groups classification system used in the National Health and Nutrition Survey in Japan was applied (10). In this system, 1,878 foods are divided into 18 food groups, including one food group of prepared foods, as a large class and 98 food groups as a small class. We selected two kinds of food that are considered to be "core," that is, representative in each of the 98 food groups. These foods were purchased from grocery stores in Himeji, Japan, and foods for a 5-d intake were weighed out, based on the amounts of food intake shown in the National Health and Nutrition Survey in Japan, 2006 (10). According to the food types, some foods were left raw and other foods were cooked by boiling, roasting or frying. These prepared foods were mixed together into each of the 18 food groups, homogenized and used as food samples for the analyses of vitamins.

Pretreatment of samples and determination of vitamins. The pretreatment of food samples was done according to the technical manual for the analysis of food composition. The seven $B$ vitamins of niacin, vitamin $B_{12}$, folic acid, pantothenic acid, riboflavin, pyridoxine and biotin, which are stable in foods and are possible to be determined by microbiological assay or HPLC, were determined in this study, as follows:

Niacin: Food samples were hydrolyzed with $\mathrm{H}_{2} \mathrm{SO}_{4}$ by autoclaving at $121^{\circ} \mathrm{C}$ for $30 \mathrm{~min}$ and neutralized with $\mathrm{NaOH}$. The niacin content of foods was measured by a microbiological assay using Lactobacillus plantarum ATCC 8014 (11). The niacin content of foods was given as $\mathrm{mgNE} / 100 \mathrm{~g}$. The content of niacin in 18 food groups was represented as the means in Table 1 .

Vitamin $\mathrm{B}_{12}$ : The determination of vitamin $\mathrm{B}_{12}$ (cyanocobalamin) in foods was assayed by a microbiological method using Lactobacillus delbrueckii subsp. lactis NBRC 3376 (12, 13). Furthermore, alkali resistance factors were also determined in food samples.

Folic acid: Food samples were treated with three enzymes, protease, $\alpha$-amylase and conjugase. The determination of folic acid in foods was performed by a microbiological assay using Lactobacillus rhamnosus NBRC 3425 (14, 15).

Pantothenic acid: The determination of pantothenic acid in food samples was conducted by a microbiological assay using Lactobacillus plantaurum ATCC 8014 (16).

Riboflavin: Food samples were treated with hydrochloric acid and decomposed enzymatically by Takadiastase B. The riboflavin content of the prepared samples was measured by $\operatorname{HPLC}(17,18)$.
Pyridoxine: The determination of pyridoxine in food samples was performed by a microbiological assay using Saccharomyces cerevisiae ATCC 9080 (19).

Biotin: Each food sample was hydrolyzed with $4.5 \mathrm{~N}$ $\mathrm{H}_{2} \mathrm{SO}_{4}$ by autoclaving at $121^{\circ} \mathrm{C}$ for $1 \mathrm{~h}$ and then neutralized with $4.5 \mathrm{~N} \mathrm{NaOH}$. Biotin contents were measured by a microbiological assay using Lactobacillus plantarum ATCC $8014(20,21)$. After culturing at $37^{\circ} \mathrm{C}$ for $18 \mathrm{~h}$, the determination of biotin was performed with the microplate reader from Biorad Co., Ltd., Tokyo at O.D. $610 \mathrm{~nm}$. The biotin content of foods was given as $\mu \mathrm{g} / 100 \mathrm{~g}$. The content of biotin in 18 food groups was represented as the means in Table 2 .

Comparative analysis. The estimated daily intake of vitamins calculated by TDS was compared with those of the National Health and Nutrition Survey in Japan, 2006, and the recommended dietary allowance (RDA) and the adequate intake (AI) recommended in Dietary Reference Intakes for Japanese-2010 edition- (DRI for Japanese, 2010) (22). Regarding vitamins other than biotin, the relationship between daily intake estimated by TDS and the daily intake reported by the National Health and Nutrition Survey in Japan, 2006, was examined to determine the reliability of the estimated daily intakes calculated by TDS.

Statistical analysis. For statistical evaluation, Spearman's rank correlation coefficient test was used to analyze the relationship between the estimated daily intake by TDS and the daily intake by the National Health and Nutrition Survey in Japan, 2006. Differences of $p<0.01$ were considered significant.

\section{RESULTS}

The daily intake of vitamins estimated by TDS was based on the amount of food intake in the National Health and Nutrition Survey in Japan, 2006, and the mean contents of vitamins in 18 food groups (Table 1 ). The niacin contents in meats, fishes and shellfishes and mushrooms ranged from $6.2-9.1 \mathrm{mg} \mathrm{NE} / 100 \mathrm{~g}$. The estimated daily intake of niacin was $22.8 \mathrm{mg} \mathrm{NE} / \mathrm{d}$ for all ages and $23.3 \mathrm{mg} \mathrm{NE} / \mathrm{d}$ for adults aged $20 \mathrm{y}$ and older (the following is the same). The niacin intake from meats was $7.3 \mathrm{mg} \mathrm{NE} / \mathrm{d}$, which accounted for $32.1 \%$ of the total intake, and that from fishes was $6.1 \mathrm{mg} \mathrm{NE} / \mathrm{d}$, accounting for $26.7 \%$.

As for vitamin $\mathrm{B}_{12}$, the content in fishes and shellfishes was $6.2 \mu \mathrm{g} / 100 \mathrm{~g}$, which was the highest in 18 food groups. The estimated daily intake of vitamin $\mathrm{B}_{12}$ was $7.39 \mu \mathrm{g} / \mathrm{d}$ and $7.63 \mu \mathrm{g} / \mathrm{d}$. The vitamin $\mathrm{B}_{12}$ intake from fishes was $5.0 \mu \mathrm{g} / \mathrm{d}$, which accounted for $67.7 \%$ of the total intake. This was more than half of the daily intake. The meats showed $1.4 \mu \mathrm{g} / \mathrm{d}$ and accounted for $18.6 \%$ of the daily intake.

Foods containing high contents of folic acid were $46.6 \mu \mathrm{g} / 100 \mathrm{~g}$ for nuts and seeds, $21.7 \mu \mathrm{g} / 100 \mathrm{~g}$ for pulses and $20.3 \mu \mathrm{g} / 100 \mathrm{~g}$ for eggs. The estimated daily intake of folic acid showed $145.5 \mu \mathrm{g} / \mathrm{d}$ and $150.7 \mu \mathrm{g} / \mathrm{d}$. The folic acid intake from vegetables was $36.0 \mu \mathrm{g} / \mathrm{d}$ and accounted for $25.1 \%$ of daily intake. Furthermore, the folic acid intake from cereals was $19.2 \mu \mathrm{g} / \mathrm{d}$ and 


\begin{tabular}{|c|c|c|c|c|c|c|c|}
\hline \multirow{3}{*}{ 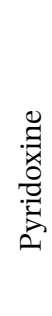 } & $\vec{E}$ & \multirow{2}{*}{ 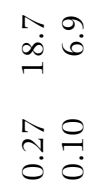 } & \multirow{2}{*}{$\begin{array}{l}\stackrel{0}{0} \\
\stackrel{0}{\circ} \\
\stackrel{0}{0}\end{array}$} & \multirow{2}{*}{ 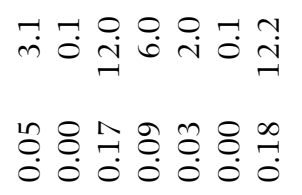 } & \multirow{2}{*}{ 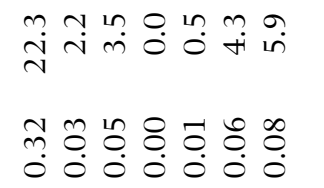 } & \multirow[b]{2}{*}{$\underset{+}{\stackrel{H}{i}}$} & \\
\hline & 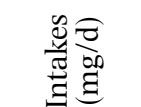 & & & & & & \\
\hline & 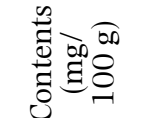 & $\stackrel{0}{:} \stackrel{0}{:}$ & $\stackrel{0}{0}$ & 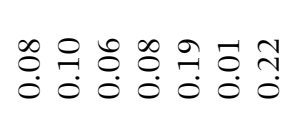 & 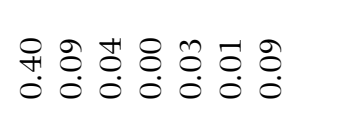 & & \\
\hline & $\stackrel{\overrightarrow{\mathrm{E}}}{\mathrm{g}}$ & $\begin{array}{l}\ln _{n}^{10} \\
\infty\end{array}$ & $\stackrel{\circ}{\circ}$ & 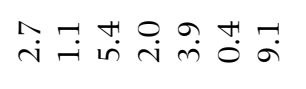 & 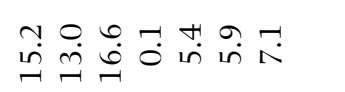 & 8 & \\
\hline 孪 & 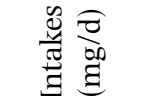 & 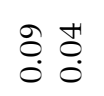 & $\stackrel{8}{8}$ & 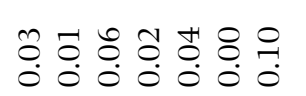 & 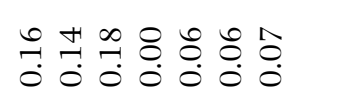 & 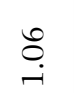 & \\
\hline$\approx$ & 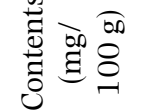 & $\begin{array}{ll}T & 0 \\
0 & 0 \\
0 & \stackrel{0}{0}\end{array}$ & $\stackrel{8}{0}$ & 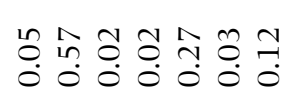 & 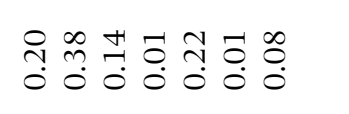 & & \\
\hline I & 至 & $\stackrel{\leftrightarrow}{\text { ì }} \stackrel{+}{n}$ & $\stackrel{\circ}{0}$ & 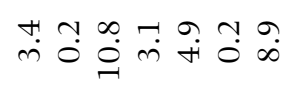 & 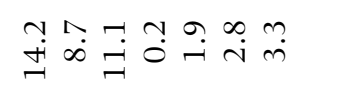 & 8 & \\
\hline 苋 & 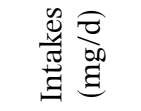 & $\stackrel{0}{0} \stackrel{0}{-}$ & $\begin{array}{l}\stackrel{8}{0} \\
\stackrel{0}{0}\end{array}$ & 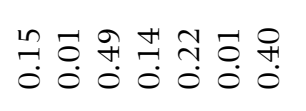 & 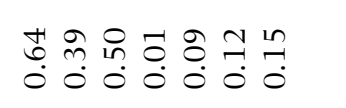 & in & \\
\hline 胥 & 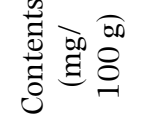 & 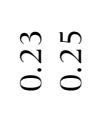 & $\stackrel{m}{0}$ & 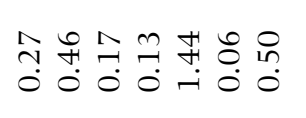 & 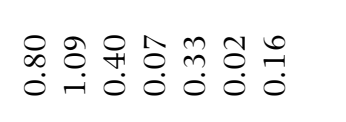 & & \\
\hline & : & $\underset{\sim}{n} \overbrace{}^{n}$ & $\stackrel{\circ}{\circ}$ & 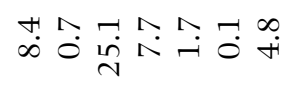 & 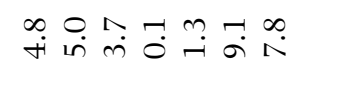 & 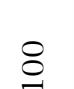 & \\
\hline 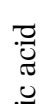 & 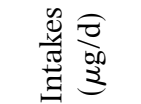 & วั้ วั้ & $\stackrel{\circ}{\circ}$ & 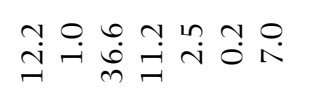 & 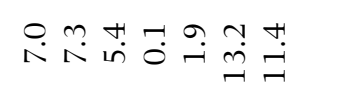 & in & \\
\hline & 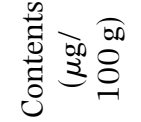 & $\stackrel{n}{+} \stackrel{\infty}{+}$ & $\stackrel{H}{0}$ & 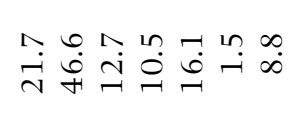 & 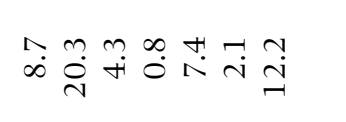 & & \\
\hline & 콩 & $\stackrel{1}{\rightarrow} \stackrel{0}{\circ}$ & $\stackrel{\circ}{0}$ & 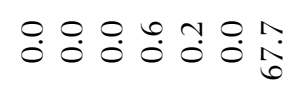 & 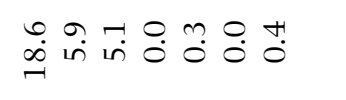 & 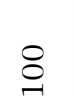 & \\
\hline $\begin{array}{l}\text { क्ष } \\
\because\end{array}$ & 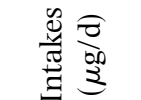 & $\begin{array}{ll}9 \\
0 \\
0 & 0 \\
0\end{array}$ & $\stackrel{8}{\circ}$ & 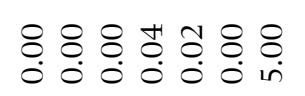 & 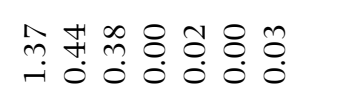 & $\stackrel{\grave{n}}{\hat{n}}$ & \\
\hline$\stackrel{\frac{\pi}{3}}{5}$ & 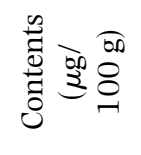 & $\begin{array}{ll}1 & 0 \\
0 & 0 \\
0 & 0\end{array}$ & $\stackrel{8}{0}$ & 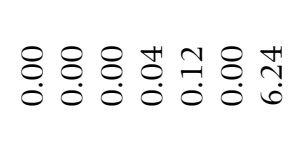 & సָ సี & & ஜ் \\
\hline & Ë & $\stackrel{\infty}{\infty} \underset{+}{\rightarrow}$ & $\overrightarrow{0}$ & 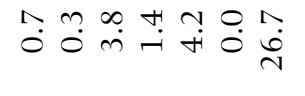 & 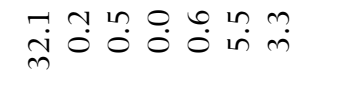 & $\underset{-}{8}$ & $\begin{array}{l}\text { 茔 } \\
\text { 㝕 }\end{array}$ \\
\hline 胥 & 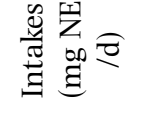 & 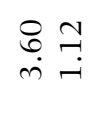 & $\ddot{0}$ & 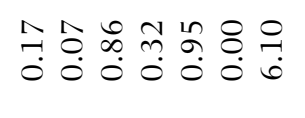 & 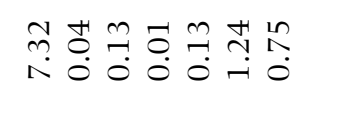 & $\begin{array}{l}\stackrel{\infty}{i} \\
\underset{i}{ }\end{array}$ & 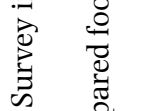 \\
\hline & 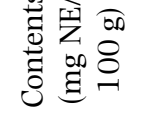 & $\begin{array}{ll}\infty & \infty \\
\infty & \infty \\
0 & \stackrel{\infty}{-i}\end{array}$ & 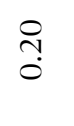 & 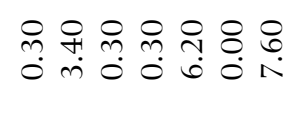 & 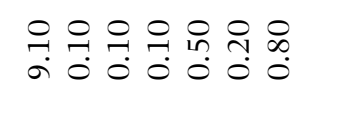 & & 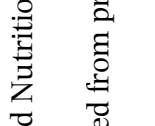 \\
\hline & 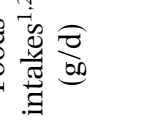 & $\begin{array}{l}\infty \\
\dot{\theta} \vec{f} \\
\dot{H}\end{array}$ & $\overparen{r}$ & 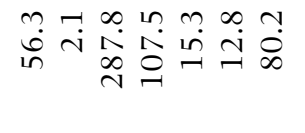 & 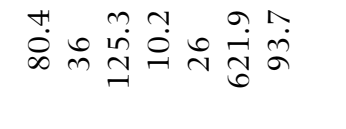 & 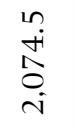 & 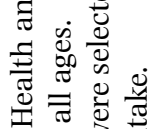 \\
\hline & 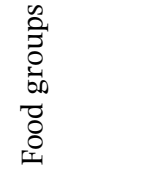 & 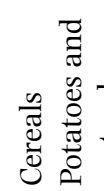 & 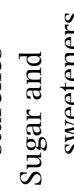 & 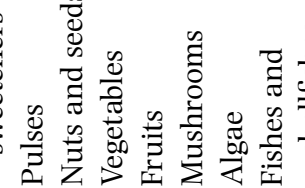 & 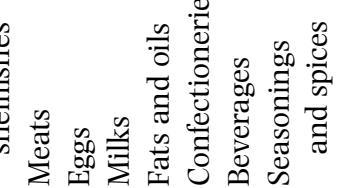 & 푱 & 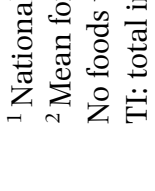 \\
\hline
\end{tabular}



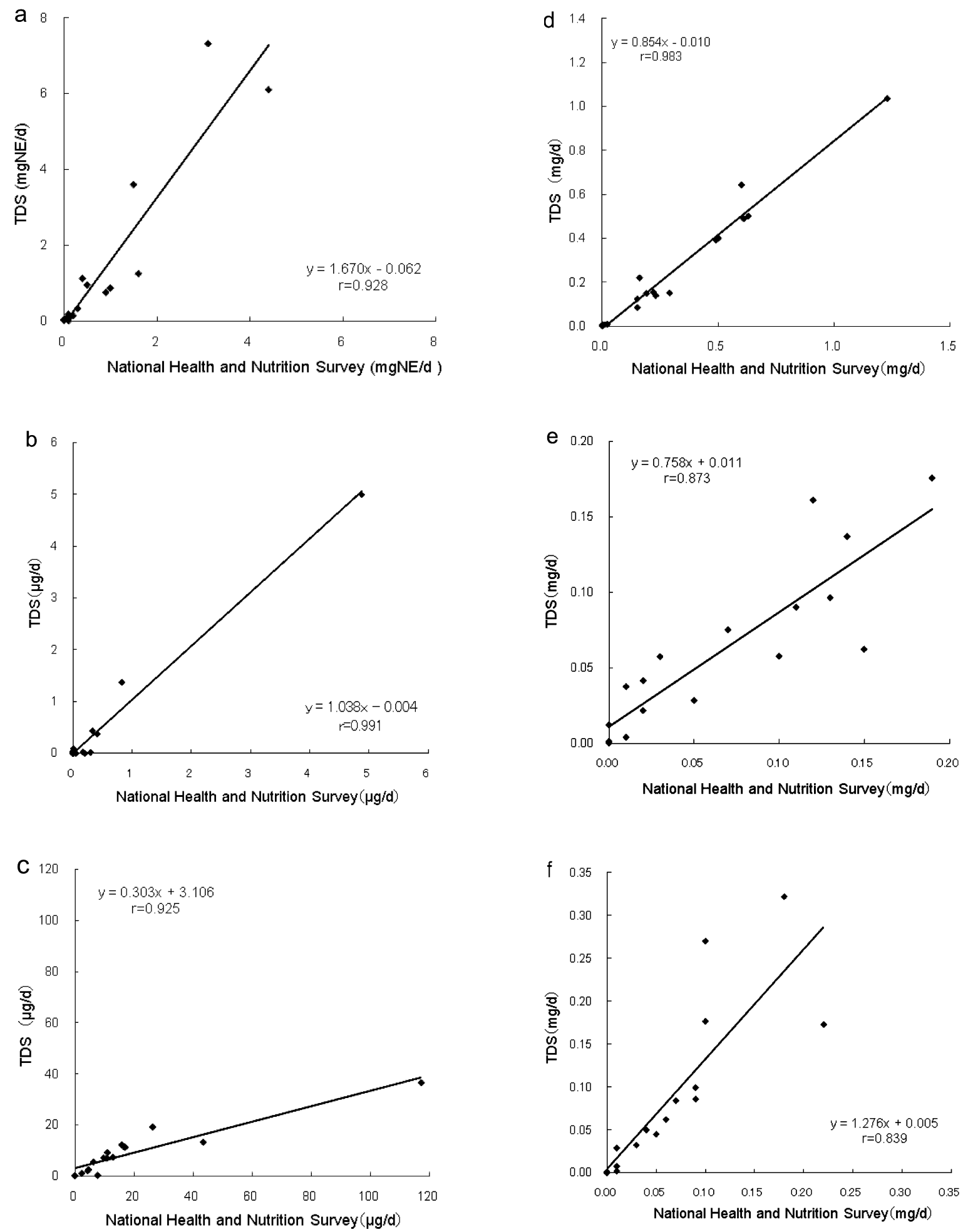

Fig. 1. Correlation of the seven B vitamins in the 18 food groups by TDS and by National Health and Nutrition Survey in Japan, 2006. a, niacin; b, vitamin $\mathrm{B}_{12}$; c, folic acid; d, pantothenic acid; e, riboflavin; f, pyridoxine.

accounted for $13.2 \%$ of the total intake.

The pantothenic acid contents of mushrooms and eggs were $1.44 \mathrm{mg}$ and $1.09 \mathrm{mg} / 100 \mathrm{~g}$, respectively. The estimated daily intake of pantothenic acid was $4.52 \mathrm{mg} / \mathrm{d}$ and $4.50 \mathrm{mg} / \mathrm{d}$. The pantothenic acid intake from cereals was $1.03 \mathrm{mg} / \mathrm{d}$ and accounted for $22.9 \%$ of the total intake. Meats, milks and vegetables showed values of $0.64 \mathrm{mg} / \mathrm{d}, 0.51 \mathrm{mg} / \mathrm{d}$ and $0.49 \mathrm{mg} / \mathrm{d}$, respectively, each of which accounted for more than $10 \%$ of daily intake.

The riboflavin content of nuts and seeds was $0.57 \mathrm{mg} / 100 \mathrm{~g}$, and that of eggs was $0.38 \mathrm{mg} / 100 \mathrm{~g}$. The estimated daily intake of riboflavin was $1.06 \mathrm{mg} / \mathrm{d}$ both for all age groups and for adults aged $20 \mathrm{y}$ and older. The riboflavin intake from meats was $0.16 \mathrm{mg} / \mathrm{d}$ and accounted for $15.2 \%$ of he total intake. Milks and eggs showed values of $0.18 \mathrm{mg} / \mathrm{d}$ and $0.14 \mathrm{mg} / \mathrm{d}$ and accounted for $16.6 \%$ and $13.0 \%$. 


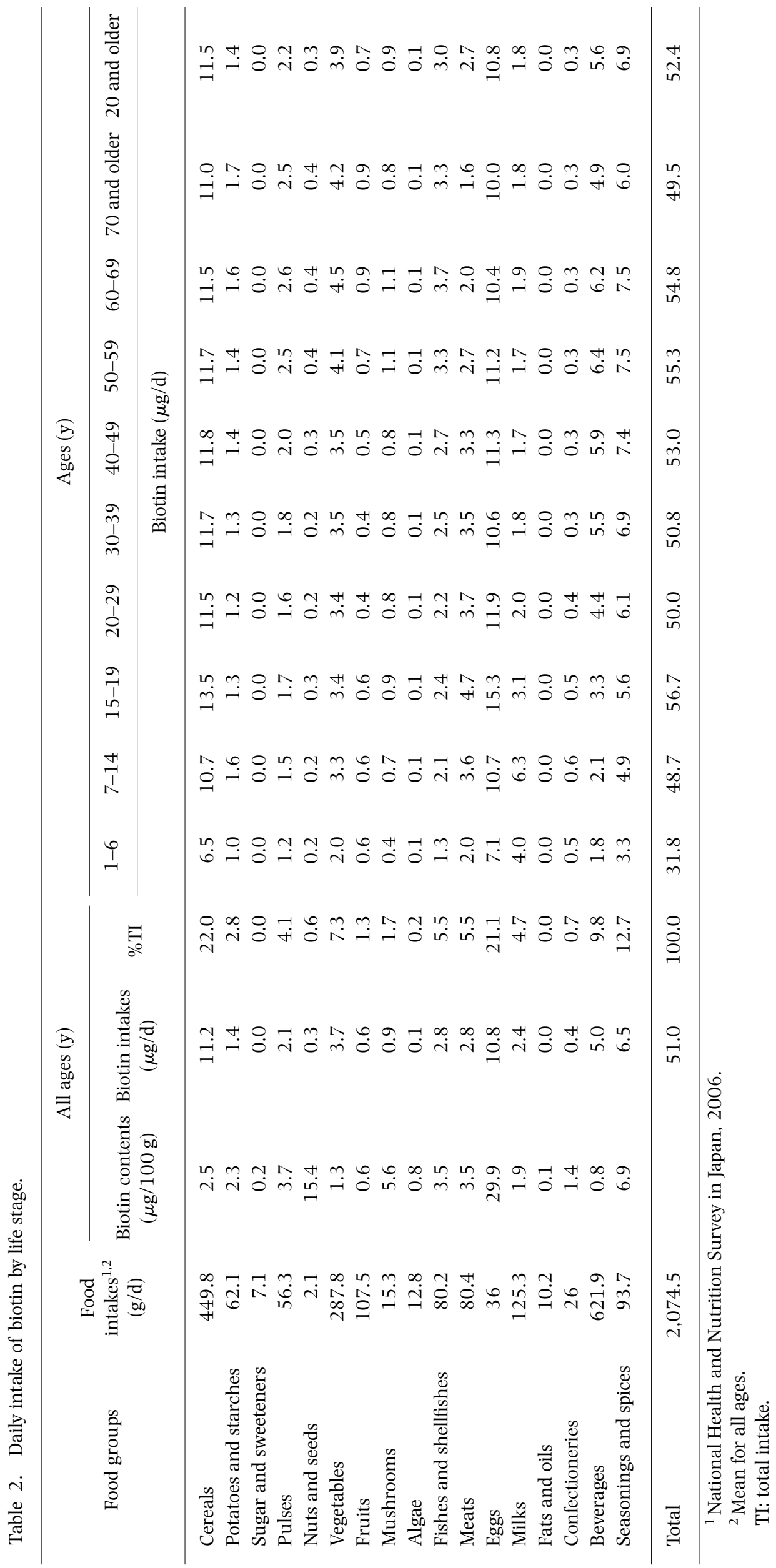


As for pyridoxine, the content of meats and fishes was $0.40 \mathrm{mg}$ and $0.22 \mathrm{mg} / 100 \mathrm{~g}$, respectively. Mushrooms also showed a high content at $0.19 \mathrm{mg} / 100 \mathrm{~g}$. The estimated daily intake of pyridoxine was $1.44 \mathrm{mg} / \mathrm{d}$ and $1.47 \mathrm{mg} / \mathrm{d}$. The pyridoxine intake from meats was $0.32 \mathrm{mg} / \mathrm{d}$ and accounted for $22.3 \%$ of the total intake, while that from cereals was $0.27 \mathrm{mg} / \mathrm{d}$ and accounted for $18.7 \%$.

The daily intake of niacin, vitamin $\mathrm{B}_{12}$, folic acid, pantothenic acid, riboflavin and pyridoxine from the respective food groups estimated by TDS was compared with that reported by the National Health and Nutrition Survey in Japan, 2006. There was a high correlation for these vitamins (Fig. 1a-f). There was an especially strong positive correlation between the estimated daily intake of niacin $(r=0.927, p<0.01)$, vitamin $\mathrm{B}_{12}$ $(r=0.991, p<0.01)$ and pantothenic acid $(r=0.983$, $p<0.01)$ with TDS. The values for daily intake estimated by TDS for niacin and pyridoxine were higher than those by the National Health and Nutrition Survey in Japan in all 18 food groups. However, the daily intake of folic acid and riboflavin estimated by TDS was lower than that indicated by the National Health and Nutrition Survey in Japan.

The biotin contents of eggs and nuts and seeds were 29.9 and $15.4 \mu \mathrm{g} / 100 \mathrm{~g}$, respectively, which were higher than those of other food groups (Table 2). The estimated daily intake of biotin was $51.0 \mu \mathrm{g} / \mathrm{d}$ for all ages and $52.4 \mu \mathrm{g} / \mathrm{d}$ for adults aged $20 \mathrm{y}$ and older. The main source of biotin was eggs and cereals, which were $10.8 \mu \mathrm{g} / \mathrm{d}$ and $11.2 \mu \mathrm{g} / \mathrm{d}$, respectively. Biotin intake from these foods contributed more than $40 \%$ to the total intake.

\section{DISCUSSION}

For adults aged $20 \mathrm{y}$ and older, the daily intake of seven B vitamins estimated by TDS were compared with the dietary reference values (RDA or AI) for adults aged 18-29 y old indicated by DRI for Japanese, 2010 (22). The estimated daily intake of 4 vitamins, namely niacin, biotin, vitamin $\mathrm{B}_{12}$, pyridoxine and niacin, examined in this study exceeded the dietary references. The estimated daily intakes of niacin and vitamin $\mathrm{B}_{12}$ were $23.3 \mathrm{mg} \mathrm{NE} / \mathrm{d}$ and $7.63 \mu \mathrm{g} / \mathrm{d}$, respectively. These were much higher compared with the $15 \mathrm{mg} \mathrm{NE} / \mathrm{d}$ for men and $11 \mathrm{mg} \mathrm{NE} / \mathrm{d}$ for women from RDA for niacin and $2.4 \mu \mathrm{g} / \mathrm{d}$ for vitamin $\mathrm{B}_{12}$ in RDA. The estimated daily intake of biotin was $52.4 \mu \mathrm{g} / \mathrm{d}$, which showed a similar value to $50 \mu \mathrm{g} / \mathrm{d}$ of the AI for adults. On the other hand, for 3 vitamins, namely folic acid, pantothenic acid and riboflavin, the dietary intakes estimated by TDS did not exceed the dietary reference values selected in Japan. The estimated dietary intake of folic acid was $150.7 \mu \mathrm{g} / \mathrm{d}$, which was markedly lower compared with $240 \mu \mathrm{g} / \mathrm{d}$ of RDA.

Regarding the daily intake estimated by TDS, it is reported that estimated daily intake of water-soluble vitamins in Japan was $1.16 \mathrm{mg}$ for thiamin, $1.10 \mathrm{mg}$ for riboflavin and $4.8 \mathrm{mg}$ for niacin in the Kinki district. In Metropolitan Tokyo in 1999, the estimated daily intake of biotin, niacin and pyridoxine was $45.1 \mu \mathrm{g} / \mathrm{d}$, $16.0 \mathrm{mg} \mathrm{NE} / \mathrm{d}$ and $1.26 \mathrm{mg} / \mathrm{d}$, respectively (8). These TDS values in the Kinki district and Metropolitan Tokyo were slightly different from those estimated by TDS in the present study. This difference may be related to the classification of food groups used by TDS. The TDS in Metropolitan Tokyo conducts vitamin determination by classifying foods into 13 food groups. However, as the foods were classified into 18 food groups in this study, the vitamin determination was performed based on foods with a similar composition of nutrients. The 18 food groups were divided by the nutritional characteristics of foods, but the 13 food groups were divided by the biochemical characteristics of the foods. The 13 food groups are very convenient for analyzing the environmental and agricultural chemicals in foods. However, in the classification of the 13 food groups, some foods containing large amounts of a certain vitamins may easily influence the mean for the food group. Furthermore, the kind of food used for analysis differed between these studies because a variety of different foods were classified into either 13 or 18 food groups. These facts may partly explain the differences in analytical values of estimated daily intakes between the 13 and 18 food groups.

For niacin $(22.8 \mathrm{mg} \mathrm{NE})$, vitamin $\mathrm{B}_{12}(7.39 \mu \mathrm{g})$, pantothenic acid $(4.52 \mathrm{mg})$, riboflavin $(1.06 \mathrm{mg})$, and pyridoxine $(1.44 \mathrm{mg})(11,23-26)$, the estimated vitamin contents obtained by TDS were the same as those of other dietary surveys. Hoppner et al. (27) reported that the prepared diet provided $14.8 \mu \mathrm{g}$ of vitamin $\mathrm{B}_{12}$ and $6.07 \mathrm{mg}$ of pantothenic acid in Canada. In NHANES II, it was estimated that the average US intake of niacin, pantothenic acid, riboflavin, and pyridoxine was $15.2 \mathrm{mg}, 3.56 \mathrm{mg}, 1.41 \mathrm{mg}$, and $1.25 \mathrm{mg}$, respectively (28). Furthermore, the pyridoxine intake was $0.91 \mathrm{mg} /$ $\mathrm{d}$ in duplicate meals and $1.12 \mathrm{mg} / \mathrm{d}$ according to dietary records kept by young Japanese women (26). As for folic acid, the daily intake was estimated to be $145.5 \mu \mathrm{g}$ by TDS in this study. The daily intake of folate was $242 \mu \mathrm{g}$ for all adults in the US according to NHANES II (29), and $190.6 \mu \mathrm{g}$ for folic acid by 3-d dietary records in young Japanese women (23). The estimated daily intake of folic acid by dietary records was lower than that contained in the actual meals. In dietary records, daily intakes are calculated using the Food Composition Tables in Japan. It was demonstrated that the folic acid content of foods listed in these Tables is relatively low. However, these findings show that the dietary intake of folic acid from meals ranged from $150-250 \mu \mathrm{g} / \mathrm{d}$.

As for the daily intake of biotin in Europe and America, Hoppner et al. (27) first demonstrated that the composite diet formulated on the basis of food consumption in Canada provided $60 \mu \mathrm{g} / \mathrm{d}$ by analysis and $60.2 \mu \mathrm{g} / \mathrm{d}$ by calculation (Table 3 ). The estimated intake of biotin was $39.9 \mu \mathrm{g} / \mathrm{d}$ in 966 women between the ages of 18 and $24 \mathrm{y}$ from 24-h dietary recall, according to data collected during NHANES II (28). However, because the concentration of biotin in foods has not yet been 
Table 3. Summary of daily biotin intake in various countries.

\begin{tabular}{|c|c|c|c|}
\hline References & $\begin{array}{l}\text { Daily intake } \\
(\mu \mathrm{g} / \mathrm{d})\end{array}$ & Subjects & Notes \\
\hline Hoppner et al. 1978 (27) & $\begin{array}{l}62.0 \\
60.0\end{array}$ & Canada & $\begin{array}{l}\text { calculation of composite diet } \\
\text { analysis }\end{array}$ \\
\hline Bull \& Buss 1982 (34) & 35.5 & 7,277 housewives & calculation by the National Food Survey, 1979 \\
\hline Murphy \& Calloway 1986 (28) & $39.9 \pm 26.8$ & 996 women (18-24 y old, USA) & 24-h recall (NHANES II) \\
\hline Lewis \& Buss 1988 (33) & $37.5(35-70)$ & 6,925 housewives & calculation by the National Food Survey, 1986 \\
\hline Bliss et al. 2000 (35) & $32 \pm 12$ & 32 subjects $(25-85$ y old $)$ & diet record for 8 consecutive days \\
\hline Iyengar et al. $2000(36)$ & $35.5 \pm 7.5$ & USA & total diet composites (FDA-TDS) \\
\hline Watanabe et al. $2004(30)$ & $\begin{array}{l}29.8-33.3 \\
54.3\end{array}$ & Adults in Tohoku district, Japan & $\begin{array}{l}\text { geometric mean using duplicate meals } \\
\text { arithmetic mean }\end{array}$ \\
\hline Saitoh \& Ushio 2004 (8) & 45.1 & Tokyo, Japan & TDS (13 food groups) \\
\hline Taniguchi et al. 2005 (37) & $\begin{array}{r}109.8 \\
92.3\end{array}$ & $\begin{array}{l}\text { Men } \\
\text { Women }\end{array}$ & Food group calculation (18 food group) \\
\hline Watanabe \& Taniguchi 2006 (9) & 60.7 & Tokyo, Japan & Re-analysis TDS (13 food groups) \\
\hline Murakami et al. 2008 (32) & $70.1 \pm 11.2$ & Osaka City, Japan & TDS (13 food groups) \\
\hline Watanabe \& Taniguchi 2009 (31) & $\begin{array}{l}51.1 \\
54.5\end{array}$ & All ages & $\begin{array}{l}\text { TDS ( } 18 \text { food groups), } 2005 \\
\text { Food group calculation ( } 98 \text { food groups) }\end{array}$ \\
\hline Present study & $\begin{array}{l}51.0 \\
52.4\end{array}$ & $\begin{array}{l}\text { All ages } \\
\text { adults aged } 24 \mathrm{y} \text { and older }\end{array}$ & TDS (18 food groups), 2006 \\
\hline
\end{tabular}

described in the Standard Tables of Food Composition in Japan (5th revised and enlarged edition), duplicate meals and TDS were used to estimate biotin intake. The biotin intake in duplicate meals was $29.3-33.3 \mu \mathrm{g} / \mathrm{d}$ in geometric means and $54.3 \mu \mathrm{g} / \mathrm{d}$ in arithmetic mean for adults (30). Two methods based on the 13 and 18 food groups were used with TDS. The dietary intake of biotin by TDS of the 13 food groups was $45.1 \mu \mathrm{g} / \mathrm{d}$ in the Tokyo Metropolitan area (8). TDS of the 18 food groups (2005) in our previous study showed $51.1 \mu \mathrm{g} / \mathrm{d}$ for all age groups (31). Furthermore, the biotin intake in the Food Group Calculation Study was estimated to be $54.5 \mu \mathrm{g} / \mathrm{d}$ for adults. These values were similar to those in the present study. Murakami et al. (32) more recently demonstrated that the estimated daily intake of biotin by TDS of the 13 food groups was $70.1 \mu \mathrm{g} / \mathrm{d}$ in Osaka City, which was about 1.5 times higher than that in the present study.

The estimated daily intake of biotin by TDS of the 18 food groups ranged from 45-55 $\mu \mathrm{g} / \mathrm{d}$ and was higher than $55 \mu \mathrm{g} / \mathrm{d}$ among the ages of 15-19 $\mathrm{y}$ and 50-59 $\mathrm{y}$. The biotin intake was derived from cereals, eggs, seasoning and spice in both groups. Cereals accounted for $22.0 \%$ of the dietary intake in all age groups and eggs accounted for $21.1 \%$. Lewis and Buss (33) reported that the average intake of biotin was $35 \mu \mathrm{g} / \mathrm{d}$ in British households, and that eggs and milks accounted for more than $50 \%$ of the biotin intake. Furthermore, the biotin intake from meats and eggs by TDS of the 13 food groups accounted for $30.8 \%$ overall in Tokyo and $50.2 \%$ in Osaka $(8,32)$. Eggs contribute highly to biotin intake, but liver, which is rich in biotin, did not contribute very much.

The daily intakes of niacin, vitamin $\mathrm{B}_{12}$, folic acid, pantothenic acid, riboflavin and pyridoxine calculated by TDS were compared with those by the National Health and Nutrition Survey in Japan, 2006. A high positive correlation between the two dietary studies was found for these six B vitamins in this study. Based on these findings, it is suggested that TDS is an effective method of dietary survey for estimating daily vitamin intake. The estimated daily intake of biotin could be determined by TDS. It is recommended that when the intake of agricultural chemicals and environmental contaminants is surveyed, the intake of micronutrients such as vitamins and minerals should also be determined at the same time.

\section{Acknowledgments}

We thank the staff of the Japan Food Research Laboratories, Nagoya, Japan, for their excellent technical assistance.

\section{REFERENCES}

1) Ministry of Education, Culture, Sports, Science and Technology, Japan. 2005. Standard Tables of Food Composition in Japan, Fifth revised and enlarged edition. Reports of the Subdivision on Resources. The Council for Science and Technology, Tokyo (in Japanese).

2) Booth SL, Pennington JAT, Sadowski JA. 1996. Dihydrovitamin $\mathrm{K}_{1}$ : Primary food sources and estimated dietary intakes in the American diet. Lipids 31: 715-720.

3) Booth SL, Pennington JAT, Sadowski JA. 1996. Food sources and dietary intakes of vitamin K-1 (phylloquinone) in the American diet: Data from the FDA total diet study. J Am Diet Assoc 96: 149-154.

4) Clarke DB, Lloyd AS. 2004. Dietary exposure estimates of isoflavones from the 1998 UK Total Diet Study. Food Addit Contam 21: 305-316.

5) Lombardi-Boccia G, Aguzzi A, Cappelloni M, Lullo GD, Lucarini M. 2003. Total-diet study: dietary intakes of macro elements and trace elements in Italy. Br J Nutr 90: $1117-1121$.

6) Chen J, Gao J. 1993. The Chinese total diet study in 1990. Part II. Nutrients. J AOAC Int 76: 1206-1213.

7) Kojima M, Aoki S, Tsuda T, Harada H. 1990. Estimation 
of daily vitamin intake by total diet study. J Jpn Soc Nutr Food Sci 43: 362-366.

8) Saitoh Y, Ushio F. 2004. Estimate of the daily dietary intake of biotin, vitamin $\mathrm{B}_{6}$ and niacin from the 1999 Tokyo total diet study. Eiyogaku Zasshi (Jpn J Nutr Diet) 62: 165-169 (in Japanese with English summary).

9) Watanabe T, Taniguchi A. 2006. Study on the estimate of dietary intake of biotin by total diet study. Nippon Eiyo Shokuryo Gakkaishi (J Jpn Soc Clin Nutr) 27: 304-312 (in Japanese with English summary).

10) Ministry of Health, Labour, and Welfare, Japan. 2009. The National Health and Nutrition Survey in Japan, 2006. Tokyo (in Japanese).

11) Shibata K, Sanada H, Yuyama S, Suzuki T. 1994. Evaluation of niacin nutrition in persons of advanced age supposed by the urinary excretion of niacin metabolites. Vitamins 68: 365-372 (in Japanese with English summary).

12) Watanabe F, Takenaka S, Abe K, Tamura Y, Nakano Y. 1996. Comparison of a microbiological assay and a fully automated chemiluminescent system for the determination of vitamin $B_{12}$ in food. J Agric Food Chem 46: 1433 1436.

13) Watanabe F. 2007. Vitamin $B_{12}$ sources and bioavailability. Exp Biol Med 232: 1266-1274.

14) Hyun TH, Tamura T. 2005. Trienzyme extraction in combination with microbiologic assay in food folate analysis: an updated review. Exp Biol Med 230: 444454.

15) Aiso K, Tamura T. 1998. Trienzyme treatment for food folate analysis: optimal $\mathrm{pH}$ and incubation time for alpha-amylase and protease treatment. J Nutr Sci Vitaminol 44: 361-370.

16) Skeggs HR, Wright LD. 1944. The use of Lactobacillus arabinosus in microbiological determination of pantothenic acid. J Biol Chem 156: 21-26.

17) Ohkawa H, Ohishi N, Yagi K. 1982. A simple method for micro-determination of flavin in human serum and whole blood by high-performance liquid chromatography. Biochem Int 4: 187-194.

18) Science and Technology Agency. 1997. Riboflabin. In: Technical Manual for Analysis of the Standard Tables of Food Composition in Japan, 5th revised, p 87-88. Tokyo (in Japanese).

19) Science and Technology Agency. 1997. Pyridoxicine. In: Technical Manual for Analysis of the Standard Tables of Food Composition in Japan, 5th revised, p 92-94. Tokyo (in Japanese).

20) Baker H, Frank O, Matovitch VB, Pasher I, Aaronson S, Hutner SH, Sobotka H. 1962. A new assay method for biotin in blood serum, urine, and tissues. Anal Biochem 3: 31-39.

21) Fukui T, Iinuma K, Oizumi J, Izumi Y. 1994. Agar plate method using Lactobacillus plantarum for biotin determination in serum and urine. J Nutr Sci Vitaminol 40: 491-498.

22) Ministry of Health, Labour, and Welfare, Japan. 2009. Dietary Reference Intakes for Japanese-2010—. Tokyo (in Japanese).

23) Hiraoka M, Yasuda K. 2000. Studies on vitamin $B_{12}$ and folate status in female students-Distribution range of serum vitamin $\mathrm{B}_{12}$ and folate levels-. Vitamins $\mathbf{7 4 :}$ 271-280 (in Japanese with English summary).

24) Kimura N, Fukuwatari T, Sasaki R, Hayakawa F, Shibata K. 2003. Vitamin intake in Japanese women college students. J Nutr Sci Vitaminol 49: 149-155.

25) Hiraoka M, Yasuda K. 1998. Study on nutritional status of thiamin and riboflavin in female students-Blood thiamin and riboflavin levels in female- Vitamins $\mathbf{7 2}$ : 679-684 (in Japanese with English summary).

26) Shibata K, Hiraoka M, Yasuda K. 1999. Study on dietary vitamin $\mathrm{B}_{6}$ intake in female students by duplicate meal method-Dietary vitamin $\mathrm{B}_{6}$ intake and serum vitamin $\mathrm{B}_{6}$ level一. Vitamins 73: 459-464 (in Japanese with English summary).

27) Hoppner K, Lampi B, Smith DC. 1978. An appraisal of the daily intakes of vitamin $\mathrm{B}_{12}$, pantothenic acid and biotin from a composite Canadian diet. Can Inst Food Sci Technol J 11: 71-74.

28) Murphy SP, Calloway DH. 1986. Nutrient intakes of women in NHANES II, emphasizing trace minerals, fiber, and phytate. J Am Diet Assoc 86: 1366-1372.

29) Subar AF, Block G, James LD. 1989. Folate intake and food sources in the US population. Am J Clin Nutr 50: 508-516.

30) Watanabe T, Ogushi M, Fukui T. 2004. Biotin status in the middle-aged and elderly in Japan. Seibutsu Shiryo Bunseki (J Anal Bio-Sci) 27: 403-408 (in Japanese with English summary).

31) Watanabe T, Taniguchi A. 2009. Estimation of dietary intake of biotin from the Japanese diet. Vitamins 83: 461-468 (in Japanese with English summary).

32) Murakami T, Yamano T, Nakama A, Mori Y. 2008. Estimation of dietary intake of biotin and its measurement uncertainty using total diet samples in Osaka, Japan. J AOAC Int 91: 1402-1408.

33) Lewis J, Buss DH. 1988. Trace nutrients. 5. Minerals and vitamins in the British household food supply. $\mathrm{Br} J$ Nutr 60: 413-424.

34) Bull NL, Buss DH. 1982. Biotin, pantothenic acid and vitamin $\mathrm{E}$ in the British household food supply. Hum Nutr Appl Nutr 36A: 190-196.

35) Bliss DZ, McLaughlin J, Jung H-J, Lowry A, Savik K, Jensen L. 2000. Comparison of the nutritional comparison of diets of persons with fecal incontinence and that of age- and gender-matched controls. J Wound Ostomy Continence Nurs 27: 90-97.

36) Iyengar GV, Wolf WR, Tanner JT, Morris ER. 2000. Content of minor and trace elements, and otganic nutrients in representative mixed total diet composites from the USA. Sci Total Environ 256: 215-226.

37) Taniguchi A, Oogushi M, Takechi R, Watanabe T. 2005. Biotin content of foods in Japan. Nippon Eiyo Shokuryo Gakkaishi (J Jpn Soc Nutr Food Sci) 58: 185-198 (in Japanese with English summary). 